\title{
A ALTERIDADE: O OUTRO COMO CRITÉRIO ${ }^{1}$
}

\section{THE OTHERNESS AS A CRITERION OF BIOETHICS}

Maria Lúcia Araújo Sadala*

SADALA, M.L.A. A alteridade: o outro como critério. Rev. Esc. Enf. USP, v. 33, n. 4, p. 355-7, dez. 1999.

Este estudo é um convite à reflexão a respeito de como o critério da alteridade - o outro como referência para os valores éticos e morais - torna-se necessário para pensar as práticas de assistência à saúde, e como transforma tais práticas, remetendo às questões da Bioética. Foi utilizada como referência a Fenomenologia Existencial.

UNITERMOS: Bioética. Assistência à saúde.

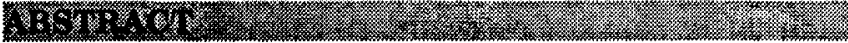

The present paper proposes questions about otherness as a fundamental criterion of Ethics and Bioethics, focusing on health care. The referencial mark used is the concept of otherness based on the Existencial Phenomenology.

UNITERMS: Bioethics. Medical assistance.

No pensamento ocidental moderno, o campo éticomoral está centrado no sujeito ético-moral consciente, dotado de vontade para controlar seus instintos, impulsos e paixões, capaz de deliberar e perceber as situações simulta-neamente determinadas e abertas, necessárias e possíveis. Este sujeito ético-moral é igualmente capaz de definir os fins da ação ético-moral como recusa da violência contra si e contra os outros, e de estabelecer uma relação justa e legítima, entre os meios e os fins da ação. O campo ético-moral, por sua vez, é formado por valores e normas, postos pelos próprios sujeitos éticomorais, na qualidade de deveres, virtudes ou bens realizáveis por todos e cada um (CHAUÍ, 1997). Nas palavras desta autora: "Valores e normas são exteriores e anteriores a nós, definidos pela sociedade e pela cultura onde vivemos; mas por outro lado somos sujeitos éticos e, portanto, capazes tanto de interiorizar valores e normas existentes quanto de criar novos valores e novas normas".

Tais comportamentos éticos contextualizam-se dentro de um mundo de relações intersubjetivas, entre mim e o outro, ambos sujeitos morais, livres e conscientes.

Esta visão contemporânea do campo ético-moral nos remete à noção da pessoa - o sujeito moral-relacionada ao outro, também sujeito - moral - ambos, eu e o outro, como sujeitos e objetos da ética. Mais propriamente, nos remete ao conceito da alteridade como critério ético fundamental.

A noção de reciprocidade como elemento fundamental na formação do sujeito social e ético - a percepção do outro como constituinte do eu - é recente na história do pensamento humano. Segundo CORRÊA (1993), apenas a partir de Hegel, em fins do século passado, o problema do outro é colocado em toda a sua agudeza. Até então predominara a moral formalista kantiana, fundada na razão universal abstrata. A partir de Hegel, os filósofos começam a se posicionar na busca do homem concreto da ação moral - o homem situado no mundo das relações interpessoais.

Podemos pensar as noções éticas, até aqui descritas, aplicadas ao campo da Bioética, nossa área de atuação. A Bioética se constitui no exame sistemático da conduta humana no campo das ciências da vida e da saúde, conduta compreendida à luz de valores e de princípios morais. Abrange os problemas éticos de todas as profissões sanitárias; as pesquisas comportamentais, independente das suas aplicações terapêuticas; os problemas sociais ligados às politicas sanitárias; e os problemas da vida animal e vegetal em relação à vida do homem ( SGRECCIA, 1996, p. 44).

1 Critério significa originalmente " aquilo que serve para julgar, aquilo pelo qual reconhecemos uma coisa e a distinguimos da outra, aquilo que dirige nossa opção" ( CORRÊA, 1993). No texto, pensamos critério como orientações que dirigem as nossas escolhas.

- Enfermeira, responsável pela disciplina Relacionamento enfermeira-paciente no Curso de Enfermagem da Faculdade de Medicina Botucatu, UNESP. 
A Bioética, como produto de uma sociedade em evolução acelerada, particularmente na área da saúde, vem exigindo dos profissionais e dos usuários dos serviços de saúde novos comportamentos e novos posicionamentos, decorrentes de situações inusitadas, criadas pela ciência e tecnologia. Nesta perspectiva questiona-se o poder da interferência do homem no campo médico-biológico, assim como a necessidade da reafirmação dos direitos dos seres humanos e dos seres vivos em geral, que potencialmente seriam ameaçados pelo domínio ilimitado dos donos da ciência.

Neste sentido, pensar a alteridade como critério fundamental da ética aplicada às situações da saúde responde às exigências atuais de se atribuir aos pacientes a competência moral e a sua posição de sujeito do próprio cuidado, consciente de si mesmo e usuário crítico dos serviços de saúde. Ao mesmo tempo, coloca os profissionais da área em posição de rever suas relações profissionais com clientes e demais categorias. Mas sobretudo, a inclusão da alteridade como critério ético confirma os valores humanos como referência para os comportamentos profissionais.

Neste estudo nos propomos a refletir a respeito $\mathrm{da}$ alteridade tendo como fundamento o referencial fenomenológico (MERLEAU PONTY, 1945 e BUBER, 1979), acrescido de outros autores que se ocuparam do tema: VIDAL (1979), DUSSEL (1984), Levinas (citado em CORRÊA, 1993) e SUSIN (1987).

Inicialmente, após notas introdutórias conceituais, abordaremos a compreensão do ser-nomundo e da constituição do mundo relacional, segundo a visão merlopontiana. Num segundo momento, traremos à reflexão a alteridade- constituição da moral e da ética, segundo os autores mencionados anteriormente.

Primeiramente, faz-se necessário compreensão do que é a pessoa, e do que é o outro (alteridade).

A pessoa, na visão dos autores estudados, configura-se como ser social, ser de relação destinado à comunicabilidade. Para MERLEAU PONTY (1945), as relações interpessoais preenchem vazios do ser-nomundo. Nesta concepção o homem se constitui pessoa pela abertura e aproximação com o outro.

BUBER (1979) fala no ser dialogal. A pessoa tem uma estrutura dialogal, o $e u$ constitui-se na referência eu-tu.

Como se constitui a pessoa-abertura no mundo, como se constitui o mundo dessa pessoa-abertura?

Para MERLEAU PONTY (1945), o homem não existe como consciência fechada em si mesmo: é o homem no mundo - o mundo das relações - e é no mundo que se conhece. É o ser-em-situação. Nunca totalmente livre, mas num mundo não totalmente acabado. A oposição e a constante tensão entre a polaridade homem-mundo mantém a constante transformação do homem e do mundo, num movimento incansável, sem fim. A dialética sem síntese, porque sempre em movimento. Ali o homem é o seu corpo: "Eu sou o meu corpo, sou espaço, sou tempo, sou lugar, sou linguagem, sou gesto". E vive experiências numa realidade concreta. Nesta realidade, neste mundo externo que habito, a minha universalidade encontra a universalidade do outro, que a limita. Então, neste mundo de relações com o outro, quando falo no eu, falo no alter ego, o eu e o eu que é o outro (SADALA, 1995).

O mundo na minha consciência, portanto, assim como o mundo na consciência do outro, não é um mundo particular. O meu mundo resulta da minha percepção do mundo, e da percepção de mim no mundo pelo outro, e da percepção que tenho do outro, resultando numa subjetividade objetividade, que Merleau Ponty chama de intersubjetividade. A constituição do mundo de relações, portanto, é um fenômeno intersubjetivo (MERLEAU PONTY, 1945).

Nesta condição de ser-em-situação, num mundo de relações já dado, a universalidade do outro me leva a uma operação seletiva para a adaptação à situação. Cada corpo, com sua estrutura própria, seleciona suas formas de adaptação, que nunca se repetem, nem com os outros, nem com ele próprio em outros momentos e outros lugares. No movimento contínuo de transformação.

Reproduzimos aqui, em tradução livre, a descrição do diálogo, como o vê MERLEAU PONTY (1945, p.81):

"Na experiência do diálogo, constitui-se entre mim e o outro um terreno comum, meu pensamento e o dele formam um só tecido, minhas falas $e$ as dele são invocadas pela interlocução, inserem-se numa operação comum da qual nenhum de nós é o criador. Há um entre-os-dois, eu e o outro somos colaboradores, numa reciprocidade perfeita coexistindo no mesmo mundo. No diálogo fico liberado de mim mesmo, os pensamentos de outrem são dele mesmo, não sou eu quem os formo, embora eu os aprenda tão logo nasçam e mesmo me antecipo a eles, assim como as abjeções de outrem arrancam de mim pensamentos que eu não sabia possuir, de tal modo que, se lhe empresto pensamentos, em troca ele me faz pensar. Somente depois, quando fico sozinho e me recordo do diálogo, fazendo deste um episódio da minha vida privada solitária, quando outrem tornou-se apenas uma ausência, é que posso, talvez, senti-lo como uma ameaça, pois desapareceu a reciprocidade que nos relacionava na concordância e na discordância". 
Pensamos que esta descrição é tão completa que, ao lê-la, é possível compreender como, a partir dessa relação dialogal entre os humanos, foi possível a constituição da linguagem $\rightarrow$ cultura $\rightarrow$ civilização $\rightarrow$ história.

A visão merlopontiana da alteridade - que ele chama intersubjetividade - pode ser complementada por visões similares de outros autores, ampliando a compreensão do conceito para os aspectos políticos, morais e éticos, conforme está descrito a seguir.

VIDAL (1979) considera que a alteridade corrige uma visão individualista e abstrata do personalismo, resgata o sujeito real concreto para a moral e permitelhe viver em mediação política.

Também para Levinas (citado em CORREA, 1993), na relação com o outro, na comunicação com ele, cria-se a consciência moral dos sujeitos: o homem sai de si mesmo pela chamada exterior do outro, que o desvela e convoca à luz. Ainda, de acordo com o mesmo autor, o outro consiste no meu limite: me obriga a retroceder de invadi-lo. "Ele é a morte das minhas expansões ingênuas e me inverte no recuo do remorso e na tentativa de velamento da vergonha". É o convite a nascer de novo. Daí o nascimento da justiça: dar a cada um o que lhe é de direito (SUSIN, 1987).

Para DUSSEL(1987), o outro se mostra ou aparece como uma revelação (epifania), como quem provoca e exige justiça. Este outro é o outro sexuado, o outro discriminado, o outro político, o outro estrangeiro, etc. $O$ outro diferente que me obriga a novas atitudes e reflexões.

Aqui nos aproximamos das questões políticas e éticas e morais. É o outro que nos traz essas questões. É diante do outro que sou chamado para essas questões. Então é diante do outro que se constituem as questões éticas e morais.

Chegamos então às relações da Ética com a alteridade. CORRÊA (1993) traz à discussão a inclusão do critério de alteridade como fundamental na aplicação dos 3 critérios da Bioética: beneficência (e não maleficência), autonomia e justiça. Um posicionar-se dos profissionais da saúde contemplando o outro - o paciente - não mais como um paciente (ser passivo e sofredor, incapaz), mas como um semelhante, numa relação simétrica (ou o mais próximo que possa ser), na qual ambos se contemplam como seres humanos únicos. Diríamos a relação dialógica, segundo BUBER (1979). Na verdade, a fundamentação dos 3 critérios na alteridade transforma a prática da assistência: passa-se a atribuir ao paciente tudo que lhe é de direito e dever e, mais que isso, a sua participação ativa, como fundamento. Sendo uma relação simétrica, também o profissional é contemplado: aparentemente tendo de ampliar suas atividades e preparar-se mais adequadamente; em contrapartida, na relação profissional se colocará de forma mais autêntica, também protegido pelos mesmos critérios da Bioética: beneficência, autonomia, justiça.

$\mathrm{Na}$ prática profissional, pensamos que tardiamente a humanidade despertou - mas enfim despertou - para as questões da alteridade. Não passivamente. Resultou de lutas históricas das classes sociais desprotegidas, há longo tempo. Apenas agora, em fins do milênio, se fala nos direitos do paciente como cidadão. Também resultou de uma solicitação do progresso científico. Há que se prepararem as sociedades para as situações espantosas para o homem comum: transplantes, clonagem de seres vivos, recriação da natureza. $\mathbf{E}$ a visão assustadora de um planeta virtualmente destruído. Tais situações extremas acirram os conflitos relacionais e exigem posicionamentos críticos.

$\mathrm{Na}$ Enfermagem as repercussões da utilização do critério da alteridade fazem-se sentir diretamente na prática da assistência, particularmente no que se refere à questão da autonomia - momento no qual enfim se reconhece que o paciente é dono do seu próprio corpo, e sujeito do seu cuidado. Porém, na nossa visão, o critério da alteridade, aceito e incorporado formalmente, mostra-se muito vulnerável no confuso e contraditório universo das relações humanas, dentro do contexto desigual da assistência à saúde no nosso país.

Porém há que se reconhecer: é um movimento em direção à evolução das práticas de saúde, e à conscientização dos profissionais em relação às questões éticas.

\section{REFERÊNCIAS BIBLIOGRÁFICAS}

BUBER, M. Eu e tu. São Paulo, Cortez/ Moraes, 1979.

CHAUI, M. Convite à filosofia. São Paulo, Ática, 1997.

CORREA, F. A. A alteridade como critério fundamental e englobante da Bioética. Campinas, 1993. 239p. Tese (Doutorado) UNICAMP-SP

DUSSEL, H. Ética da libertação. (Hipóteses fundamentais). Concilium, v. 192, n. 2, p. 83, 1984.

MERLEAU PONTY, M. Phénoménologie de la perception, Paris, Gallimard, 1945.

SADALA, M. L. A. Estar com o paciente: a possibilidade de uma maneira autêntica de cuidar. São Paulo, 1995. 235p. Tese (Doutorado). Escola de Enfermagem, Universidade de São Paulo.

SGRECCIA, E. Manual de bioética 1. Fundamentos e ética biomédica. São Paulo, Loyola, 1996.

SUSIN, L. C. O esquecimento do "outro"na história do ocidente. Rev. Ecles. Bras., v. 47, p. 820-38, 1987.

VIDAL, M. Moral de atitudes. Trad. Pe. Ivo Montanhese. Aparecida, Editora Santuário, 1979. 